\title{
Erratum to: Toward a comparative theory of agents
}

\section{Rafael Capurro}

Published online: 28 April 2012

(C) Springer-Verlag London Limited 2012

Erratum to: AI \& Soc

DOI 10.1007/s00146-011-0334-6

Unfortunately, in the original publication of the article, the text of Section 4 except the quote by Kang 2011, 110 was duplicated. The author would like to apologize for this.

The online version of the original article can be found under doi:10.1007/s00146-011-0334-6.

R. Capurro $(\square)$

Distinguished Researcher in Information Ethics,

School of Information Studies,

University of Wisconsin-Milwaukee,

Milwaukee, WI, USA

e-mail: rafael@capurro.de 